\section{De la versión} del pasado en el manual a la del cine en la historia escolar*

\section{Da versão do passado no manual à do cine na história escolar}

The Version of Past in School History: From Handbooks to Films

\section{Wilson Armado Acosta Jiménez ${ }^{* *}$}

* Este análisis hace parte del proyecto de investigación de doctorado: "Historia y educación del tiempo presente en la cinematografía latinoamericana del narcotráfico, entre 1990 y el 2010", que se realiza en el programa Doctorado Interinstitucional en Educación de la Universidad Pedagógica Nacional - Universidad Distrital Francisco José de Caldas y Universidad del Valle. El director del proyecto de investigación es el profesor Adolfo León Atehortúa Cruz.

** Profesor del Departamento de Ciencias Sociales, Facultad de Humanidades de la Universidad Pedagógica Nacional. Licenciado en Ciencias Sociales de la Universidad Distrital Francisco José de Caldas. Magíster en Sociología de la Educación de la Universidad Pedagógica Nacional. Estudiante del Doctorado Interinstitucional en Educación. Correo electrónico:wilaracostaj@gmail.com,wacosta@pedagogica. edu.co

\section{Resumen}

El objetivo de este artículo es el de esbozar y analizar los rasgos que se han ido configurando con el paso de la versión del pasado que se contaba en los manuales a la que se muestra con el cine, en la historia escolar. Se aborda la producción académica sobre el encuentro entre la escuela y los filmes a partir de las elaboraciones conceptuales y metodológicas de la pedagogía y la didáctica de la historia. Y se problematizan algunas de las propuestas didácticas en historia, que toman como referente las películas que tratan de problemáticas sociales del pasado reciente y lejano.

\section{Palabras clave}

Historia escolar, cine, educación, escuela, pedagogía, didáctica de la historia

\section{Resumo}

O objetivo deste artigo é o de esboçar e analisar os rasgos, que se hão ido configurando com o passo da versão do passado, que se contava nos manuais à que se mostram com o cine, na história escolar. Aborda-se a produção acadêmica sobre o encontro entre a escola e os filmes, a partir das elaborações conceptuais e metodológicas da pedagogia e a didática na história, que assumem como referente os filmes que tratam de problemáticas sociais do passado contemporâneo e remoto.

\section{Palavras chave}

História escolar, cine, educação, escola, pedagogia, didática da história

\section{Abstract}

This article attempts to outline and analize the features arisen when the version of past in school history, as told in handbooks, moved towards film versions. The study addressess the academic production on the school-film relationships from conceptual and methodological developments on the pedagogy and didactics of history. Authors also analyze some didactic proposals on history, which move around films on problems from recent and distant past.

\section{Key words}

School history, film, education, school, pedagogy, didactics of history

Fecha de recepción: Marzo 3 de 2015 Fecha de aprobación: Junio 12 de 2015

Pedagogía y Saberes No. 42 Universidad Pedagógica Nacional Facultad de Educación. 2015, pp. 117-129 


\section{Introducción}

En cuanto forma pedagógica, el cine a menudo pone en juego problemas que conciernen al discurso público, al debate y a la manera de hacer política de modo diverso y en ocasiones espectacular, si nos referimos a películas que abordan el racismo, desafían la homofobia o transmiten representaciones provocativas que tratan de la guerra, la violencia, la masculinidad, el sexismo o la pobreza.

Giroux

$\mathrm{L}$ as producciones cinematográficas hoy en día tienen un gran impacto cultural, pues hacen parte de los repertorios que identifican a los individuos y a los colectivos sociales. El cine se nos presenta como una ventana indiscreta que se abre para mostrarnos lugares, épocas, personajes y otras maneras de vivir, de las cuales a diario no tendríamos noticia. Los filmes se han ido posicionando en el espectro amplio de la cultura por lo que nos muestran y porque han cumplido un rol importante en la educación de nuestros sentimientos, recuerdos, percepciones y valoraciones de lo que somos y de lo que son los otros. Por esto, según Giroux (2003), el cine hace parte de una pedagogía pública que responde a la confrontación de intereses ideológicos, disputas por el poder y al posicionamiento de determinada verdad; sin embargo, en la perspectiva de este autor no se hace un análisis profundo de lo que implica el cine en el aula, las relaciones que se generan, los cuestionamientos y las afectaciones a lo que Cuesta (1998) denomina como el código disciplinar de la historia escolar.

Con este artículo, se proponen tres objetivos: a. esbozar y analizar los rasgos que se han ido configurando con el paso de la versión del pasado que se contaba en los manuales a la que se muestra con el cine, en la historia escolar. b. Abordar la producción académica sobre el encuentro entre la escuela y los filmes a partir de las elaboraciones conceptuales y metodológicas de la pedagogía y la didáctica de la historia. c. Analizar algunas de las propuestas didácticas en historia, que se han publicado en la web o en libros, y que toman como referente las películas que tratan sobre problemáticas sociales del pasado reciente y lejano.

Para dar cuenta de estos objetivos el artículo se ha dividido en cuatro apartados: en el primero, se exploran las posturas más recientes y que circulan en nuestro medio, de la pedagogía sobre el vínculo de los saberes escolares y la proyección de filmes como proceso formativo. En el segundo, se identifican tres condiciones socioculturales, que se han ido configurando a lo largo del siglo $\mathrm{xx}$, y que hacen posible la integración de películas a las prácticas de enseñanza.
En el tercero, se examinan propuestas didácticas en historia que asumen el uso del cine como estrategia metodológica y temática, y que estarían en la perspectiva de afectar rasgos del código disciplinar de la historia escolar. Y en el último, se presentan las conclusiones como preguntas abiertas a las maneras como el cine irrumpe y se adapta a las condiciones socioculturales y políticas de la historia escolar.

\section{El devenir de un encuentro: pedagogía, escuela y cine}

El siglo xx nos dejó transformaciones que hoy tiene un impacto significativo en la vida diaria. Sin lugar a dudas, los cambios tecnológicos han tenido unas implicaciones en las maneras como nos relacionamos con los otros y con nosotros mismos. Esto sería redundar en un sentido común que ya hace parte de las suposiciones con las cuales actuamos a diario. Sin embargo, la reflexión sobre el cine en la formación de las masas se ha desarrollado entre la duda y la certeza. Parece que para unos es innegable el papel que juegan las producciones cinematográficas en las concepciones individuales y colectivas sobre lo que somos; y para otros, las películas se reducen a ser parte del entretenimiento que hoy nos inunda por los medios masivos de comunicación, y no serían más que distracción. En este apartado se exploran estas dudas y certezas sobre la función que cumplen las películas en el devenir del encuentro entre pedagogía, escuela y cine.

Con el desarrollo de la industria cinematográfica se llegó a suponer que este podría reemplazar los manuales escolares, a los maestros y las prácticas de enseñanzay aprendizaje que se dan en la escuela. Esta concepción propuso ver en los productos audiovisuales toda una gama de posibilidades y mostraba cómo el niño podría acercarse a imágenes reales del mundo, de la ciencia y de la cultura ${ }^{1}$. En términos generales, durante la primera mitad del siglo xx se concibió que el cine aportaba a transformar las maneras de transmitir conocimientos y hasta incidía en la adquisición

1 Según Serra, en los albores del siglo xx, Thomas Alba Edison ya planteaba unas consideraciones sobre el cinematógrafo en la cultura, y su impacto en las instituciones educativas. Declaraciones tales como "los libros pronto llegarán a ser cosas añejas en las escuelas públicas"; "los estudiantes serán instruidos por la acción visual"; "es posible enseñar cada rama del conocimiento humano por medio del cinematógrafo"; "nuestro sistema educacional se cambiará completamente en los próximos diez años” son recogidas en un artículo traducido y reproducido por en El Monitor de la Educación Común en el año de 1916, en donde también se reseña que este inventor desarrolló un sistema para la educación de los niños donde todo se enseña por medio del cinema, que viene probando con público en general y con grupos de niños en particular, al que se denomina "juvenil cuerpo de censores". (2011, p. 52) 
de hábitos para la vida en la ciudad. Se ampliaron los debates sobre las oportunidades de llevar el cine al aparato escolar, para transmitir los contenidos de las disciplinas escolares ${ }^{2}$.

En la pedagogía se va a ir configurando la preocupación por las posibilidades y relaciones entre las producciones cinematográficas y el aparato escolar, a partir del momento mismo en el cual el cine se proyecta como un medio masivo de difusión de los ideales, valores y conceptos del orden social capitalista (Giroux, 2003). Esto, sin olvidar que el aparato escolar para inicios del siglo XX se había constituido en uno de los dispositivos encargados de regular las maneras de producir sujetos disciplinados, dóciles y productivos (Varela, y Álavez, 1991.) De manera particular, según Serra, la educación escolar y el cine se encuadran dentro de un régimen de visibilidad que explicaría la relación entre estos como "la idea de máquinas productoras de un orden visual que funciona como constructor de un régimen de verdad" (2011, p. 41).

De allí, que se dé una relación compleja entre la escuela y el cine, pues la primera ha sido producida por unas determinadas coordenadas de acción y de discurso, o, al decir de Dussel (2009), por unas relaciones de poder-saber. La escuela como dispositivo cultural ha regulado la relación con las imágenes fijas y estas han estado en las ilustraciones de los textos, en las láminas, en las paredes, en los corredores y en las salas de los edificios escolares. Sin embargo, el cine irrumpe de manera profunda en las maneras de transmitir y recibir información y conocimientos de la vida y de la ciencia, a través de imágenes en movimiento. En este sentido, Dussel señala que el dispositivo escolar haría parte de la "formación de una cultura de la imagen, y no al costado, como solemos hacerlo" (2009, p. 181). Esto se ubicaría como parte de

[...] la discusión sobre las transformaciones que traen consigo los nuevos medios, que cuestionan algunos de los fundamentos de la organización de poderes y saberes en la escuela. ¿Por qué "cultura de la imagen" y no "medios"? En primer lugar, el acercamiento a la cuestión de los medios, como parte de un proyecto de investigación y acción que viene desarrollándose desde hace algunos años, parte del análisis pedagógico del lenguaje audiovisual. Las

2 En el caso colombiano, se puede referenciar el estudio de Álvarez Gallego (2003), que aporta a comprender cómo "la inclusión del cine en el ámbito escolar no solo planteó ímpetus modernizadores. En paralelo con ellos se desplegaron una serie de debates alrededor de lo que el cinematógrafo representaba para la enseñanza. ¿Puede reemplazar libros, maestros y escuelas? ¿Desafía modos de transmisión de la cultura ya instituidos? ¿Puede ocupar el lugar de otros modos de conocer? ¿Cuál es el papel de las instituciones educativas frente a él?" (citado por Serra, 2011, p. 51) preguntas centrales de este análisis tienen que ver con pensar qué pasa con el lenguaje de las imágenes en un contexto escolar, qué tipo de conocimiento o efectos produce y cuál es su relación con formas de saber/poder instituidas. (Dussel, 2009, p. 181)

Siguiendo los planteamientos de Dussel, lo que se ha constituido es un régimen visual del cual se puede afirmar que va más allá de ser un conjunto de imágenes, y se posicionan "como discursos visuales que construyen posiciones, y que están inscritos en prácticas sociales, estrechamente asociados con las instituciones que nos otorgan el 'derecho de mirada' (entre ellas, la escuela, que organiza un campo de lo visible y lo invisible, de lo bello y de lo feo)" (2009, p. 181). Hoy encontramos que para la pedagogía y para la investigación educativa, es necesario asumir una perspectiva que se fundamente en los estudios visuales (Mirzoeff, 1999; Schwartz y Przyblyski, 2004. Citado por Dussel, 2009, p. 181). Estos se proponen desde un interés interdisciplinario que, "en vez de tratar las imágenes como símbolos iconográficos, las trata como acontecimientos, esto es, como los efectos de una red en la que operan los sujetos y que, a su vez, condicionan su libertad de acción" (Mirzoeff, 2005, p. 11. Citado por Dussel, 2009, p. 181).

Por esto, al analizar desde el punto de vista de la pedagogía moderna las relaciones que se han configurado entre escuela y cine, es importante comprender la manera como desde la escolarización se contribuyó a la formación de sujetos visuales modernos ${ }^{3}$. De acuerdo con Dussel, la pregunta que puede orientar este proceso es la de "cómo interactúa la institución escolar con estas nuevas visualidades que se están estructurando en estos tiempos, no desde afuera sino desde adentro de una cierta cultura visual" (2009, p. 182).

Ahora bien, esta cultura visual se debate entre dos actitudes frente al conocimiento: la primera, que correspondería a la masificación de lo audiovisual y en donde imperan rasgos como la disolución de distancias, la ampliación al extremo de las imágenes en

3 Pestalozzi y otros subrayaron el valor de la educación de la percepción y de los sentidos en términos de "distancia objetiva”. En la educación visual promovida desde la escuela, ver se volvió equivalente a saber y a creer ("ver para creer"), en una articulación que sigue operando con firmeza en nuestras formas de conocer. No había mediación ni opacidad en el acto de ver; las diferencias fueron pensadas como anormalidades o desviaciones patológicas. No menos importante fue la participación de la escuela en la organización de un sujeto social, el espectador moderno, que se suponía tendría al mismo tiempo una cierta imparcialidad -distancia entre la observación y la acción (refrenar los impulsos, intervenirlos por la reflexión),-y también compromiso, esto es, una inversión emocional y afectiva que es necesaria para suscitar la afiliación política en la esfera pública. (Boltanski, 1999, p. 33. Citado por Dussel, 2009, p. 185) 
la pantalla, el presentismo como forma de mostrar lo inmediato, la exacerbación de las sensaciones, el ritmo acelerado, la emocionalidad y el sentimentalismo como efectos en los espectadores. Y la segunda, que sería la actitud del dispositivo escolar que propone el valor de lo crítico, el permanente análisis, la moderación en la manifestación de las emociones, las expresiones letradas antes que lo oral y lo corporal, y una obsesión por educar al observador a distancia. Concluye Dussel que

\begin{abstract}
[...] es necesario entender que no es tanto la imagen en sí lo que causa cierto efecto, sino la imagen en el contexto de ciertas culturas visuales, de tecnologías, de formas de relación con esas imágenes. Por eso, de lo que se trata es de trabajar sobre regímenes visuales, que definen lo que es visible y lo invisible, y también modos y posiciones del mirar y del ser visto. Una pedagogía de la imagen debería empezar por entender que las imágenes no son meras cuestiones icónicas, o suponer que alcanza con entender la semiología de una imagen suelta, sino que hace falta entender cómo funcionan en un cierto discurso visual, en una forma particular de llegarnos y de conmovernos. Las imágenes son prácticas sociales: ésta es una verdad de Perogrullo, pero no menos cierta ni menos importante para pensar en las pedagogías de la imagen. (2009, p. 191)
\end{abstract}

Para "cerrar" las reflexiones que se han planteado en este apartado, considero que es significativo tener en cuenta a la hora de problematizar los vínculos entre escuela y cine, desde la pedagogía, la pregunta que plantea Serra (2006) sobre si el cine se constituye en una experiencia pedagógica. Pero más allá de la respuesta afirmativa o de entenderla como un proceso de formación, el cuestionamiento que nos deja Serra es el de comprender cómo se da este proceso en el ámbito escolar:

\begin{abstract}
Menos sencillo resulta dar cuenta de dónde reside esa experiencia, qué es lo que la hace pedagógica, cuáles son los parámetros para ubicarla como tal, cómo opera sobre nosotros, qué capacidad de inscribir marcas en nosotros tiene. ¿Es su capacidad de transmitir la cultura, de formatear identidades, de inscribir "estructuras de sentimientos" lo que hace del ver cine una práctica que debe ser tenida en cuenta por la pedagogía? (Serra, 2006, p. 146)
\end{abstract}

Ahora bien, esta perspectiva implica que desde la pedagogía y la didáctica de la historia pensaríamos el cine en la escuela como un dispositivo dentro de otro dispositivo; es decir, "una forma de mirar dentro de la otra, una mirada que a su vez es mirada por otra, un orden simbólico leído desde otro orden" (Serra, 2006, p. 149). En este sentido, el conocimiento sobre el pasado y el presente se estaría dando desde un doble dispositivo, que va a mediar en la manera como los individuos interiorizan su vivencia y comprenden lo que acontece, en el devenir histórico y social ${ }^{4}$. A pesar de las problemáticas que se dan con la entrada del cine al aula, y que este puede terminar atrapado en las prácticas y en las lógicas de la didactización, es decir, como un texto o recurso que se instrumentaliza en el uso cotidiano de actividades, el cine se puede mirar como el otro que irrumpe en medio de un aparato institucionalizado, pero que no deja de estar producido por fuerzas y sujetos en tensión. Por esto,

En la experiencia escolar, abrir las puertas al cine bien podría ser un modo de que lógicas, voces e imágenes extrañas, extranjeras, la visiten, suspendan sus certezas por un momento y hagan otra cosa de ella. Si el ojo de la pantalla es capaz de alterar el régimen de lo subjetivo (Kuri, 2004), quizá debamos otorgarle algún crédito para que habite e interrogue la escena escolar. Quizá sea ese dislocamiento que lo otro nos produce el que habilite a que otra mirada pedagógica tenga lugar. (Serra, 2006, p. 153)

Es en esta provocación sobre lo que implica pensar desde lo pedagógico, la relación del cine con la escuela, la que permitirá el análisis de manera particular de las implicaciones que se han producido en la enseñanza de la historia. En el siguiente apartado se identificarán las condiciones que han hecho posible el uso didáctico del cine.

\section{Condiciones de posibilidad para ver cine en la clase de historia}

Llegará un momento en que a los niños en las escuelas se les enseñe prácticamente todo a través de películas; nunca se verán más obligados a leer libros de Historia.

\section{W. Griffith ${ }^{5}$}

En este segundo apartado se caracterizan tres condiciones que hacen posible la entrada del cine a las clases de historia, en el contexto latinoamericano y de

4 Serra va a distinguir dos grupos de problemas, que se generan con esta condición de doble dispositivo: el primero es aquel que tiene que ver con los efectos que produce sumar lentes para mirar la realidad, ampliar el registro de textos para pensar algo. Es aquí donde ubico una de las mayores dificultades y a la vez la enorme potencialidad que el cine trae a la escuela. El segundo grupo se refiere a las condiciones de posibilidad de esta doble lectura. ¿Qué es lo que hace posible este encastre? ¿Qué es lo que cae en el discurso escolar cuando el cine entra en él? (2006, p. 149)

5 David Wark Griffith hizo esta afirmación en 1915. (Citado en Caparrós Lera, 2007, p. 30) 
España: la investigación histórica del cine como fuente, el desarrollo del mundo de las cinematografías y el ingreso al aula de aparatos para la proyección de imágenes audiovisuales. Estas condiciones, a su vez, están en el marco de una relación de tensión, que se da entre la mediación de la perspectiva de cultura letrada y la que se da con la cultura oral-icónica. La primera tiene como una de sus características la de centrarse en la lectura y memorización de textos que contaban una versión del pasado, por esto la importancia del manual escolar, y se posiciona y desarrolla bajo la égida del modo de educación tradicional-elitista. La segunda se presenta como una mediación con la mirada y la interpretación de un discurso audiovisual, en esta adquieren relevancia los filmes, y se viene realizando bajo el manto del modo de educación tecnocrático de masas, en el cual se pueden identificar cambios en las maneras de trasmitir la información y el conocimiento del pasado (Cfr. Cuesta, 1997).

\section{a. Investigación histórica del cine como fuente}

En la perspectiva de conocer asuntos del pasado de una sociedad a través de los filmes por estas producidas, fue pionero el alemán Siegfried Kracauer. Esta investigación es considera el punto de partida en el campo de la historiografía, para el desarrollo posterior de proyectos que estudiarán en el cine, entre otros asuntos, la conformación de identidades, los referentes de memoria histórica y las representaciones de los conflictos sociales ${ }^{6}$. La apertura de este camino no ha sido fácil, pues, hasta la década de 1970, en la historiografía de Europa, aparte del citado trabajo de Kracauer, no se habían desarrollado y fundamentado de manera más amplia y profunda los estudios históricos a partir del cine.

Será el historiador Ferro quien continuará llamando la atención sobre la manera como los filmes han impacto en las sociedades, porque estos se han ido constituyendo en el punto de referencia para las nuevas generaciones sobre los grandes acontecimientos y los modos de vida de culturas lejanas y cercanas.

6 El resultado de su trabajo fue la publicación en 1946 del libro De Caligari a Hitler. En esta investigación se analizan los filmes realizados en el período que comprende desde la presentación del filme El gabinete del Dr. Caligari (Alemania, Wiene, 1919) a la toma del poder por parte de Hitler (1933). Según Kracauer, en las películas de una nación se puede identificar su mentalidad de manera más explícita que en otras creaciones artísticas. El objetivo de Kracauer era demostrar que las tendencias psicológicas dominantes de 1918-1933, y de manera especial el nazismo, estarían presentes en las producciones fílmicas de la República de Weimar. Entre otros aspectos se estudiaron las características ideológicas en el cine expresionista alemán y sus vínculos con el escenario político.
Según Ferro, la cuestión de indagar sobre la visión fílmica de la historia es un problema importante que se justifica por el impacto que tienen las imágenes audiovisuales, a partir del desarrollo tecnológico que han alcanzado y por el tiempo que dedican las personas a mirar televisión o asistiendo al cine, y dejando de lado la lectura de libros. De acuerdo con las observaciones de este autor, las versiones del pasado que circulan en la sociedad, fundamentalmente, estarían producidas por las narrativas audiovisuales que se han masificado de manera vertiginosa ${ }^{7}$.

Otro aporte es del sociólogo Sorlin, quien va a señalar que el cine no es solamente un espejo de la realidad social, sino que las imágenes audiovisuales se configuran como representaciones de esa realidad ya que "la película, como todas las representaciones, es una simplificación y una interpretación, su elaboración depende de la personalidad de quien la realiza, de su conocimiento del tema, del destinatario al cual se dirige. Esto es válido para todos los documentos, textos o imágenes, pero no es tan visible con los textos como lo es con las películas. El cine ofrece a los historiadores un modo de reflexionar sobre las fuentes que utilizan y sobre los conceptos de los cuales se sirven" (Sorlin, 2008, p. 22).

Sin embargo, frente a las postura de Ferro y Sorlin, que se centraron en el estudio de las condiciones de enunciación de las formas y los contenidos de lo fílmico, están los planteamientos del historiador norteamericano Rosenstone (2008), quien en la indagación por las relaciones entre cine e historia se va a "radicalizar" y a tomar un aire más profundo. A este historiador le interesa comprender cómo el medio audiovisual, que está sujeto a los códigos de la narrativa de la ficción, se encarga de mostrar unas imágenes del pasado. Por ello, se hace necesario ir más allá de la noción de neutralidad en el medio y complejizar cómo un tema puede ser trasladado desde la página a la pantalla sin que se produzcan alteraciones significativas ${ }^{8}$.

7 "[...] cuando se visiona una película que habla principalmente del pasado, para comenzar, la vemos con una mirada que yo denominaría positivista; mirada positivista que quiere decir erudita, una verificación de la autenticidad. Por ejemplo, en una película sobre los inicios de la Guerra del 14 , si se ven los soldados con un casco (entonces no llevaban casco, sino casquete y hasta 1917 no cambiaron), y si saben esto y los espectadores son franceses, al ver el film con los soldados con casco en 1914, dirán: ¡Esto es falso! Esto quiere decir que, al mismo tiempo, están contentos, pero también sospechan. El espectador está contento porque, por vez primera, sabe alguna cosa. Sabe más que el que ha realizado la película, pero en cambio no tendrá confianza en el film. Esto es lo que llamo la mirada erudita. (Ferro, 1987, p. 21)

8 Cambiar desde lo oral a lo escrito y a la pantalla, añadir imágenes, sonido, color, movimiento y drama, es alterar la forma en que leemos, vemos, percibimos y pensamos el pasado. 
En elámbito de España, los estudios académicos que se pueden considerar pioneros son los realizados por los profesores Hueso (1991) y Caparrós Lera (1997). Del profesor Hueso se destaca la importancia del "cine histórico" por la continuidad e importancia que ha alcanzado durante el siglo xx, y afirma que "por todo ello es lógico que haya surgido la necesidad creciente y permanente de investigar la significación de estos films y su evolución a lo largo de la historia del cine, que también es la de nuestro siglo" (p. 13). El profesor Caparrós Lera, y de acuerdo con Martínez Gil, viene utilizando "el film como herramienta de investigación para profundizar en el humanismo y ciencias sociales, considerándolo como testimonio de la sociedad, reflejo de las mentalidades y retrato de la evolución del mundo contemporáneo" (2013, p. 367).

En cuanto a los aportes de Latinoamérica a los estudios históricos a partir de las películas, se puede decir que estos han sido recientes en relación con otras historiografías, como se señalaba en los párrafos anteriores. Estos trabajos ya hacen parte del acumulado analítico que circula en artículos, libros, ponencias y seminarios de pregrado y posgrado, que, por su diversidad de contenidos y metodologías, sería pretencioso incluir en este artículo9. El profesor Alvira llama la atención sobre algunos de los trabajos de historia y filmes, que han logrado superar con "éxito la barrera del lenguaje que el cine presenta a los historiadores y que además han completado su análisis recurriendo a otro tipo de documentos" en su país, Argentina (2011, p. 147).

\section{b. Desarrollo del mundo de las cinematografías}

El mundo del cine es plural y amplio en sus producciones y maneras de expresión, esto lo constituye en una tecnología de la comunicación que se presenta como una forma cultural de las relaciones sociales y del acontecer histórico. Al asumir el cine como un dispositivo que captura las vivencias del sentir,

Todos estos elementos son parte de la práctica de la historia en una película, para la que aún no disponemos de una apropiada etiqueta. Tampoco tenemos un buen conocimiento de sus coordenadas, cómo y dónde se sienta en el tiempo, el espacio y en relación con los otros discursos. (Rosenstone, 2008, p. 18)

9 Otras referencias a investigaciones en la perspectiva de relacionar cine e historia por países: Brasil [Ferreira dos Santos, J. (2013); Flores, S. (2013); Barrenha, N. (2013)]; Chile [Salinas, C., Stange., H., y Santa Cruz, A. (2013)]; Venezuela [Bermúdez Briñez, N. 2008]; Argentina [Feld, y Stites Mor, (2009); Mestaman, M. (2008); Manzano, V. (2001 y 2004); y Kriger, C. (2009)]; México [Cuarterolo, A. (2013); Lusnich, A. (2013); Sala. J. (2013); Garavelli, C. (2013); Campo, J. (2013); Pérez Bernal, (2012)]; y Colombia [Pérez Murillo, (2008); Ospina, (2010); Beverly, (2011)]. los ambientes socio-espaciales, los intercambios económicos y las fuerzas políticas de momentos históricos ${ }^{10}$. Las producciones fílmicas se convirtieron, a lo largo del siglo Xx, en el arte que logra mostrar de manera explícita, profunda e íntima los conflictos y el devenir de la vida moderna. Esto, porque se constituye en una tecnología que

[...] permite la circulación, la movilidad de la mirada y la restitución de lo efímero, pero también como un medio de expresión constitutivo de una nueva colectividad, esto es, un tipo de público receptivo a las imágenes y con una mirada capaz de asumir la dificultad de percepción del espacio y el tiempo que la modernidad trae consigo. (Peña Ospina, 2012, p. 122)

En esta configuración se ubica el cine independiente, de autor o moderno ${ }^{11}$, que si bien en algunos se ha planteado que no tiene un carácter pedagógico, sino formativo como una experiencia, viene a ser un cuestionamiento profundo de las maneras como se concibe a la sociedad y al individuo. En este cine las imágenes que se ponen van en contracorriente de las maneras de existir, de las formas de relaciones sociales, de la misma estructura de la vida política

10 Por otra parte, el dispositivo, en términos foucaultianos, es una disposición de todos estos elementos con un propósito: disciplinar los cuerpos, normalizar las existencias para configurar un orden del discurso, un orden de la representación de la realidad (Foucault en Deleuze, 155-163). ¿Cuál es la gravedad de esta comprensión? Desnaturalizar la realidad: cuestionar las maneras hegemónicas de entenderla, poner en suspenso, por de pronto, las comprensiones positivas de la modernidad y los procesos de modernización asociados e inscritos en colonialidades diversas. (...) captar los procesos por sobre sus contingencias, sus fragmentos en relación a la totalidad social. El cine deberá entenderse como un dispositivo que, en este caso, debe implicar "una red de relaciones entre cosas, hombres y prácticas sociales. No es una idea, sino una máquina. No es un objeto, sino un conjunto de ellos". (Salinas, 2012, p. 127)

11 El cine moderno surge bajo dos lemas estéticos e ideológicos: mostrar una realidad objetiva del ser humano, y no hay nada más objetivo que el sujeto, su condición de sujeto insatisfecho pues no siempre el ser humano alcanza el objeto deseo, llámese amor, fortuna o éxito como lo mostraba el cine clásico. El segundo lema del cine moderno es el concepto de cine de autor. Aunque el cine de autor existió desde casi el comienzo del cine, como lo mencioné en la introducción, la conceptualización y la política que lo promueven aparece de una forma evidente en el cine moderno. El cine moderno se caracteriza por la validación del director como autor único del filme, él es quien debe expresar su arte siendo la cabeza creativa del filme y mostrando su visión del mundo (en el cine clásico el director era considerado un técnico más, eran más importante las ideas que aportaba el productor y el estrellato estaba en el actor o actriz; sin embargo, claro que hubo grandes directores -autores en el cine clásico que lograron imponerse creativamente a pesar del cine escapista y de narración rígida que les exigían los estudios-). (Gutiérrez Correa, 2014, p. 6) 
y económica. Este tipo de películas ha contado con tendencias y maneras de entender la representación de la realidad y su apuesta se ha centrado en ámbitos de lo ético y lo político. El cinema novo brasileiro, que durante las décadas de los 60 y 70 se constituyó en referente del cine de ruptura con los cánones del cine de los emporios y las industrias culturales.

De este modo, llego a un corpus amplio de cine latinoamericano, en ningún caso totalizadory acabado, una panorámica que intenta encauzar y a la vez abrir espacios y por qué no, tránsitos. Películas que vienen a tejer una red a partir de las huellas que dejan sus estéticas y sus temáticas abordadas. Estas últimas se mantienen constantes con la tradición, "configurando la personalidad del cine latinoamericano" desde los años 60, es decir, "preocupaciones sociales, políticas y éticas, que se manifiestan en la mayoría de las películas más recientes, cualesquiera que sean los géneros o las estéticas en las que se inscriban", como el exilio en Cuba, la violencia en Brasil, el "acercamiento a los grandes problemas nacionales de la crisis económica y de la memoria de la dictadura desde la perspectiva de historias personales y anecdóticas en Argentina o Uruguay" (Valenzuela Prado, 2010, p. 143)

Directores de cine como Glauber Rocha, Nelson Pereira Do Santos, Domingo de Oliveira, entre otros, se movilizaron en torno a las imágenes del brasileño negro, indígena, el campesino y, a la manera de Buñuel, de retratar los olvidados de las sociedades capitalistas (Braz, 2002). En estas propuestas se evidencian preocupaciones que se relacionan con el cuestionamiento de los valores, los proyectos políticos, las desigualdades sociales, las condiciones de pobreza en las ciudades y otras problemáticas que ya no se idealizan, sino que se presentan como condiciones de la vida social y política de los pueblos latinoamericanos ${ }^{12}$. En esta tendencia va a estar presente la discusión sobre la importancia del cine como mecanismo que cuestiona al individuo y al colectivo sobre sus condiciones de existencia y el origen de los conflictos sociales.

La otra tendencia que ha predominado en el mundo del cine es la de Hollywood, que se produce para el público y en la que se muestra el deber ser de la escuela (Matilda, 1996), el referente de los maestros comprometidos (La sociedad de los poetas muertos), la reconstrucción de acontecimientos históricos como casos ejemplarizantes (Corazón valiente, 1989, y El patriota, 2000), y el anuncio de un fututo catastrófico y a la vez de salvación (Armagedón, 1998), que evidencian una filmografía en donde predomina la reificación del

12 Es importante ubicar para el caso colombiano la obra cinematográfica de directores como Víctor Gaviria y Antonio Dorado, quienes han abordado problemáticas como el narcotráfico y la violencia: Sumas y restas (2004) y El rey (2004). pasado, el presente y el futuro. En los anteriores casos, se identifica un uso de una pedagogía pública que ejemplariza y naturaliza cierta manera de entender los valores, el orden social, los conflictos económicos, las proezas y los fracasos de la sociedad. Este cine contribuye a consolidar unas maneras de entender el tipo de sociedad hegemónico, el tipo de valores que se constituyen en universales, y los supuestos sobre el discurso histórico ${ }^{13}$.

\section{c. Ingreso al aula de nuevas tecnologías para la proyección de audiovisuales}

Es en las décadas de 1960 y 1970 cuando el cine se masifica en las grandes ciudades y la asistencia de público se convierte en un asunto común y corriente. La escuela no es ajena a este cambio y se van dando pasos para que este se integre a las clases de historia. Se empiezan a reemplazar textos escritos por películas que pueden ser ejemplo de procesos históricos; es el caso de la película Dantón (1983), que se va a utilizar para explicar la Revolución Francesa. Según Paladino (2006), en el contexto argentino en esos años se dio un aumento significativo de la proyección de películas en la de educación media y superior. De acuerdo con este autor, los jóvenes fueron al cine, aumentaron las salas de cine arte y las películas adquirieron prestigio como obra artística y cultural ${ }^{14}$. Es a partir de la década de 1980, con la incorporación de la videocasetera, como se determina el cambio en las maneras de llevar el cine al aula.

En pocos años se incrementaron las instituciones equipadas, aumentó la oferta de títulos de películas disponibles a la hora de planificar una actividad docente y se multiplicó la visión de films en las aulas. La novedad tecnológica cambió por completo el modo de ser espectador. Desapareció la sala oscura,

13 "Las películas de Hollywood hacen algo más que entretener, ofrecen posiciones al sujeto, movilizan deseos, nos influyen inconscientemente y nos ayudan a construir un fresco de la cultura americana. Profundamente ligadas a las relaciones materiales y simbólicas de poder, las películas producen e incorporan ideologías que representan el resultado de luchas que marcaron las realidades históricas del poder y las angustias de los tiempos; también son un despliegue de poder en el sentido de desempeñan un papel que conecta la producción de placer y el significado de los mecanismos y la práctica de máquinas poderosamente pedagógicas. Dicho simple y brevemente: las películas entretienen y enseñan a la vez". (Giroux, 2003, p. 15)

14 "La ebullición cinéfila, en mayor o menor medida, pronto repercutió en las aulas. Sin la obligatoriedad de un correlato curricular, las funciones proyectadas en escuelas secundarias, profesorados y universidades acogieron características del modelo de cine club". (Paladino, 2006, p. 137) 
la pantalla blanca, el haz de luz atravesando el espacio. Junto con la videocasetera apareció el televisor de 20 pulgadas - con frecuencia, instalado no en el mejor ángulo de visión sino próximo al enchufe y frente a ventanas sin cortinas para oscurecer el salón-. Para el docente, todavía fue difícil disponer de información sobre lo que proyectaba. (Paladino, 2006, p. 138)

En las dos últimas dos décadas las transformaciones con respecto al consumo del cine se han intensificado. En este periodo se consolidaron los estudios sobre cine y las disciplinas sociales, así como la divulgación de publicaciones de crítica y teoría cinematográfica. También se extendió en las ciudades el consumo de la televisión por cable, la construcción de grandes infraestructuras de salas, la posibilidad de acceder a cámaras de filmación digital en los hogares y en las escuelas se han adquirido nuevos equipos como los proyectores, pantallas digitales, televisores plasma, entre otros ${ }^{15}$.

Estas condiciones de posibilidad han incidido en la manera como el cine ha ingresado a la clase de historia escolar, ya sea por las preocupaciones de investigación en la disciplina histórica, por la producción y circulación de cinematografías que se despliegan en escenarios no formales, ni convencionales, y porque las innovaciones tecnológicas les permite llevar a los estudiantes películas hasta en sus celulares.

\section{Miremos lo que somos con una película}

Ahora es más frecuente que se use el cine para enseñar historia, pero la opinión [negativa] ha cambiado poco, porque los historiadores no están formados para analizar las imágenes. Por lo tanto, sienten miedo y no tienen la misma seguridad que cuando trabajan con textos escritos.

Ferro

En la génesis de la historia como disciplina escolar y en la configuración de un imaginario común del pasado,

15 "Sin embargo, más allá de experiencias ocasionales (hay casos de docentes que trabajaron escritura y rodaje de guiones con los alumnos, escenificación de actos escolares, investigaciones documentales filmadas, etc.), en términos generales el ámbito escolar no registró variantes en el modo de consumo. En la escuela de hoy, la proyección de películas está social e institucionalmente aceptada; lo que no significa que haya logrado la legitimación esperable, pues para algunos proyectar una película en clase todavía suele asociarse con la pérdida de tiempo, el ocio, la nada. Lo cierto es que no sabemos qué hacen los docentes con el cine: cuántos lo utilizan, cómo, en qué contexto, qué inconvenientes encuentran, cuál es la repercusión de estas actividades". (Paladino, 2006, p. 139) han estado las imágenes en los relatos y en la iconografía de los procesos de formación del conocimiento del pasado. En el marco de esta tradición escolar y cultural van a irrumpir las imágenes en movimiento como la representación de situaciones, de hechos, de personajes, de condiciones, de tramas, de relatos y argumentos que hablan de la sociedad, de las ideologías, de las crisis y de momentos neurálgicos de ayer y de hoy. Ahora bien, el estudio de las maneras como irrumpe en la enseñanza de la historia es una oportunidad para cuestionar las maneras como se ha entendido la práctica didáctica y la práctica social de los supuestos que movilizan el ingreso del lenguaje audiovisual.

En este sentido, la Didáctica de la Historia, como un campo emergente en el estudio, sistematización y producción de conocimientos sobre lo que acontece con las prácticas de enseñanza de lo histórico en el ámbito escolar, va a contribuir a la formulación de propuestas y al análisis de las mismas (Cfr. Rodríguez y Acosta, 2007). Este campo es disperso y ha generado que la producción y circulación de sus elaboraciones conceptuales y metodológicas sean realizadas por académicos de disciplinas sociales (historiadores, sociólogos, políticos, geógrafos y pedagogos), quienes han contribuido a comprender y a configurar este campo. Sin embargo, no se ha logrado la constitución de líneas de indagación y producción académica que no queden supeditas a las regulaciones de las políticas educativas, la producción de la disciplina histórica o el eficientísimo de las lógicas de la competencia educativa ${ }^{16}$.

\section{a. Balance de propuestas didácticas}

Es en este campo donde se han presentado orientaciones metodológicas, experiencias de trabajo en el aula con películas, análisis de filmes desde el punto de vista de la enseñanza de la historia y recomendaciones de películas para el desarrollo de determinados contenidos de la historia escolar. En Colombia, por ejemplo,

16 Esto explica que las propuestas didácticas más difundidas y demandadas desde mediados de la década de los noventa busquen optimizar los procesos de aprendizaje mediante la adopción o incorporación de códigos que garanticen enseñanza efectiva, sin que medien ejercicios de análisis sistemático, sobre el contexto educativo, político y cultural, sobre el saber que se enseña en relación con el campo disciplinar o temático de referencia, o sobre la experiencia de los profesores en el área de su especialidad. En busca de la eficiencia en el resultado educativo, la enseñanza ha transitado de lo que denomina $\mathrm{M}$. Narodowski (1999) el ideal pansófico de enseñar todo a todos y de la "utopía sociopolítica" de la formación de un cierto tipo de hombre, en una perspectiva moderna, universalista, hacia las "nuevas utopías hiperadaptativas", caracterizadas ya no por el para qué de la enseñanza, sino por el cómo, pregunta propia de la instrumentalización del saber. (Rodríguez, y Acosta, 2007, p. 50-51) 
se encuentra la publicación de Acosta (2000), quien presenta una experiencia de la manera como se puede cambiar la enseñanza de las ciencias sociales a través del cine, entendiendo que el cine se puede considerar como una herramienta para la construcción del conocimiento de lo social en la educación básica. En el contexto de España se ubican otros trabajos como el Amar Rodríguez (2003), que reitera la opción del cine como un recurso didáctico y cómo este puede contribuir al disfrute de la vivencia fílmica en las clases de historia.

De la editorial española Graó se referencian dos publicaciones que aportan a la reflexión del cine como contenido y medio para la enseñanza de lo histórico: la primera es un monográfico de la revista Íber (1997), en donde se exploran las implicaciones, vínculos y propuestas entre el cine, la historia y la geografía; la segunda, es un libro de Breu (2012) en donde se analiza la importancia del documental como estrategia educativa y se ofrecen diez actividades. Y por último, los trabajos sobre enseñanza de la historia contemporánea por intermedio del cine (Caparrós Lera, 2007); la reflexión sobre la necesidad de abordar la historia de África subsahariana a través del cine de este continente, de Ordóñez del Pino (2011). En el marco del centenario de la Primera Guerra Mundial, y al contar este hecho histórico con una amplia filmografía, esta se presentó como una posibilidad para estudiar con los estudiantes este hecho histórico por parte López Iñiguez (2014).

También se contó conla elaboración deun manual de Historia de América de las últimas décadas del siglo XX, a partir de una colección de documentales y filmes latinoamericanos con el "objetivo de estudiar la realidad de este espacio mediante la aplicación de fuentes distintas a las tradicionales" (Fuentes, y Murillo, 2005. Citado por Bermúdez Briñez, 2008, p. 110). Y en el contexto mexicano, está la experiencia de la profesora Pacheco (2004), asesora de la Universidad Pedagógica de México, en donde "se hizo un acercamiento a la estructura familiar y su proyección en la sociedad mexicana de los años 40 y 50, utilizando como recursos las películas Nosotros los pobres (1948) y Ustedes los ricos (1948)" (Citado en Bermúdez Briñez, 2008, p. 110).

Este conjunto de propuestas y estudios en la didáctica de la historia son una muestra de las prácticas y discursos que se vienen realizando alrededor de las posibilidades que se han configurado entre cine y enseñanza del pasado. Aún hace falta una mirada más sistemática y analítica de los procesos formativos que adelantan profesores de la educación básica y media, en relación con problemáticas sociales relevantes en perspectiva histórica y a partir de cinematografías latinoamericanas.

\section{b. Afectar las prácticas de enseñanza}

En los ámbitos de la enseñanza y el aprendizaje de la historia estas propuestas apuestan por transformar las maneras instituidas de desarrollar las clases. Existe una postura por romper con el imperio de los manuales de historia y generar otras dinámicas que contribuyan a la formación de sujetos, con la capacidad de extrañarse de las miradas que se nos imponen. Sin embargo, quedan inquietudes sobre el tipo de supuestos que están orientando estas propuestas didácticas. Por ejemplo, se ha planteado que para el estudio del cine en la clase de historia, se debería lograr un ejercicio de análisis interdisciplinar, cuestión que no se alcanza en la mayoría de los casos. En la mirada y la interpretación que se hace de las películas, predomina la ilustración de temáticas, en correspondencia con el grado y la edad del estudiante.

En la propuesta de Acosta (2000) se parte de dos presupuestos sobre la enseñanza de las ciencias sociales y la historia, para la proyección de las películas: el primero es que esta se encuentra suscrita a la crisis que se ha dado en la enseñanza de estas disciplinas escolares, y es necesario transformarlas. Y el otro es el de asumir que al diseñar actividades didácticas con películas, esto bastaría para romper con las maneras como tradicionalmente se ha enseñado historia. Las películas como un recurso didáctico que motivaría a los estudiantes dejarían por fuera del aula la lógica memorística y propenderían por una actitud más reflexiva y critica de las realidades sociales. En este punto, en las propuestas consultadas existe un reiterado interés por distanciarse de las maneras tradicionales de enseñanza la historia escolar.

\section{c. Articular las elaboraciones historiográficas y la disciplina escolar}

Otra cuestión para resaltar en las propuestas analizadas es la manera como se van incorporando los desarrollos conceptuales y metodológicos de las investigaciones que se han realizado sobre problemáticas sociales específicas en el campo de la disciplina histórica. Asunto de viejo cuño y que puede entenderse como una tensión constitutiva entre la disciplina escolar y la académica. En este punto, la mirada y el estudio de las películas no se pueden dar por fuera de estas elaboraciones. Por ejemplo, en la propuesta sobre la enseñanza de la Primera Guerra Mundial y su filmografía, lo primero que se presenta es el panorama de los principales enfoques historiográficos, en lo metodológico y lo conceptual. Después se eligen los filmes para mirar, se realizan explicaciones previas, los alumnos elaboran fichas 
técnicas de las películas y, finalmente, los estudiantes realizan el siguiente cuestionario:

- ¿Consideras que alguna de las películas vistas tuvo en su momento un papel patriótico y de exaltación de los valores militares? Justifica la respuesta.

- ¿Qué películas muestran mejor las estrategias utilizadas durante la Primera Guerra Mundial y las matanzas que provocaron las mismas?

- ¿Cómo reflejan estas películas la evolución del cine a lo largo del siglo Xx? Justifica tu respuesta desde un punto de vista técnico e ideológico. (López Iñiguez, 2014, p. 6)

Se puede decir que a partir de esta actividad, se muestra cierto interés por lograr la articulación de los desarrollos de la historiografía con las prácticas de enseñanza del pasado en lo escolar, así como vincular el estudio de información impresa con la visual. En esta perspectiva se encuentran las propuestas examinadas por Bermúdez Briñez, para quien

\begin{abstract}
La cuestión fundamental no estriba en defender una fuente o una forma específica de adquirir conocimiento histórico, privilegiando a una solamente, sino en saber exactamente el uso que puede dársele a cada dentro de una situación de aprendizaje formalizado o no. No se pretende crear la falsa idea de que el libro pierde valor o interés frente a la imagen audiovisual, ambos se complementan y ofrecen un discurso histórico con características diferentes. Un documental o una película de ficción pueden conducir al espectador a interesarse en el tema y desarrollar una indagación mucho más profunda que lo lleve a obtener un mayor conocimiento del asunto narrado. (2008, p. 111)
\end{abstract}

Con esta articulación de discursos sobre los hechos históricos en los procesos formativos que se darían con estas propuestas, se supone que los estudiantes lograrían: el contraste de fuentes, la apropiación de categorías de análisis, una sensibilización sobre los conflictos del pasado y el presente, una comprensión compleja de los procesos macro y micro de las sociedades, y por último, provocar en los docentes y los estudiantes el deseo por elaborar una versión desnaturalizada del pasado y alejada del sentido común.

\section{d. El peso de las condiciones escolares}

Sin embargo, así se dé una valoración positiva de los estudiantes que trabajan a partir del cine los contenidos históricos, en la institución escolar continúa persistiendo el peso de las estructuras de los tiempos, los espacios, los contenidos temáticos, la escasa formación de los maestros en estos ámbitos culturales y el consumo indiscriminado en los estudiantes del cine comercial. De allí la necesidad de cualificar el análisis de los filmes para ir tomado distancia de considerar el cine como un pasatiempo, como un distractor que se utiliza en las clases para ejemplificar una situación o sencillamente para que pasen las horas de la clase. Es el momento de tomar el cine como objeto de investigación, enseñanza, aprendizaje y formación para la vida. El problema no es el de encontrar los errores históricos que aparecen en las películas, pues a eso no nos dedicamos cuando leemos un libro de historia, sino a la problematización de la versión del pasado que se construye y a la manera como circula en nuestros medios (Cfr. Rosestone, 1997).

\section{Y ahora qué... ¿nos vemos en cine?}

Esta práctica de investigación crítica no depende de un método, sino que se apoya en la disciplina; no requiere una metodología rica, sino que pide una pedagogía pobre, es decir, prácticas que nos permitan exponernos, que nos lleven a la calle, que nos disloquen. Quisiera elaborar algo en relación con lo que esa práctica de investigación e-ducativa crítica es y comenzaré con un ejemplo: el ejemplo del caminar (y anotar). Entonces, educar la mirada será una invitación a caminar.

\section{Masschelein}

Las realizaciones audiovisuales hacen parte de la agenda educativa y cultural de las sociedades latinoamericanas; el cine y la televisión vienen divulgando maneras de sentir, pensar y actuar frente a las realidades del mundo contemporáneo (Serra, 2011, Alegria, y Duarte, 2005, Dussel, y Gutiérrez, 2006). En las películas, la cuestión educativa es importante en la medida en que estas no educan por sí mismas; es necesario un ejercicio de formación, de análisis y de indagación que permita una comprensión y ampliación de los referentes del relato histórico y del posicionamiento político. Al decir de Sánchez (2000), es indispensable que desde el campo pedagógico y didáctico, se elaboren y apropien referentes analíticos que aporten a formar en los sujetos, y en particular a los niños y a los jóvenes, interpretaciones que vayan más allá de lo evidente y lo naturalizado por el sentido común, las industrias culturales y los mass media.

El cine es la oportunidad de desarrollar una hermenéutica que transforma la crítica, la formación y la experiencia. En este sentido, la formación en el pasado común y en los problemas sociales no se asumen como una cuestión donde se transmiten los valores y las verdades instituidas, sino que implica que el sujeto se 
posiciona políticamente y reconfigura sus referentes de identidad. Estaría abierta la posibilidad para que el cine sea más que una herramienta que facilita los procesos de aprendizaje-enseñanza y se asuma como una opción para la formación de la mirada, que es inquietante y agudiza el pensamiento. Una mirada que se adentra en el sujeto que observa, pero que a la vez se ve provocado por las imágenes que se entrecruzan con la experiencia de quien hace las veces de espectador, estudiante y profesor.

Las películas en las clases de historia se posicionan como textos abiertos, que van interpelando las maneras como se enseña, los contenidos que se trabajan, los propósitos que se persiguen y, en últimas, el sentido de esta disciplina escolar en el contexto actual. Por lo expuesto en los apartados anteriores, el cine no se limita a reemplazar un texto escrito por uno audiovisual, sino que se constituye en un ejercicio de formación de la mirada para docentes y estudiantes. Sin lugar a dudas, el desarrollo de la disciplina histórica en cuanto a las investigaciones sobre problemáticas del pasado y sus relaciones con las expresiones cinematográficas se posiciona como un referente muy importante para los procesos didácticos que se pueden llevar al aula.

También el ejercicio de sistematizar experiencias de enseñanza de la historia a partir de películas es un aporte para comprender y acentuar los cambios que se vienen dando en las características metodológicas y de contenidos de la historia escolar. Queda abierta la pregunta por los asuntos que acontecen en aspectos de la disciplina escolar, como la opción por transformar las rutinas, los tiempos y los espacios para el estudio y la comprensión del pasado. El cine en la escuela y la cultura se ha ido configurando en una experiencia, en el sentido de decir que acontece algo distinto, genera otras preguntas, cuestiona los conceptos e ideas que se han naturalizado y abre las puertas a pensar de otros modos.

\section{Referencias bibliográficas}

Acosta, W. (2000). Las ciencias sociales a través del cine: el cine como herramienta en la construcción del conocimiento de las Ciencias Sociales en la básica secundaria. Bogotá: Magisterio.

Alegria, J. y Duarte, R, (2005). Um sonho, um belo sonho: considerações sobre a gênese das relações entre educação e cinema no Brasil. En: Revista diálogo educacional, 5, (15). 11-26. Curitiba: Pontifícia Universidade Católica do Paraná.

Álvarez, A. (2003). Los medios de comunicación y la sociedad educadora, ¿ya no es necesaria la escuela? Bogotá: Magisterio.
Amar, V. (2003). Comprender y disfrutar el cine. La gran pantalla como recurso educativo. Huelva: Grupo Comunicar Ediciones.

Barrenha, N. (2013). La función educativa del cine y el Instituto Nacional de Cine Educativo en el gobierno de Getulio Vargas. En: Lusnich, A. (2013) (coord.). Representación y revolución en el cine latinoamericano del período clásico-industrial: Argentina, Brasil, México. Madrid: CeALCI- Fundación Carolina. Disponible en: www.fundacioncarolina.es

Bermúdez, N. (2008). El cine y el video: recursos didácticos para el estudio y enseñanza de la historia. En: Revista de Teoría y Didáctica de las Ciencias Sociales. Mérida, Enero-diciembre, (13), 101-123.

Breu, R. (2012). La historia a través del cine: 10 propuestas didácticas para secundaria y bachillerato. Barcelona: Graó.

Campo, J. (2013). La Revolución mexicana y los documentales de compilación. Estudio de Memorias de un mexicano (Carmen Toscano, 1950). En: Lusnich, A. (2013) (coord.). Representación y revolución en el cine latinoamericano del período clásico-industrial: Argentina, Brasil, México. Madrid: CeALCI- Fundación Carolina. Disponible en: www.fundacioncarolina.es

Caparrós, J. (1997). 100 películas sobre historia contemporánea. Madrid: Alianza Editorial.

Caparrós, J. (2007). Enseñar la historia contemporánea a través del cine de ficción. En: Quaderns de cine, (1), 25-35. Recuperado el 16 de enero del 2015 de: http:// hdl.handle.net/10045/11372

Cuarterolo, A. (2013). Representaciones de la revolución independentista en el cine argentino del período silente. En: Lusnich, A. (2013) (coord.). Representación y revolución en el cine latinoamericano del período clásico-industrial: Argentina, Brasil, México. Madrid: CeAlci- Fundación Carolina. Disponible en: www. fundacioncarolina.es

Cuesta, R. (1997). Sociogénesis de una disciplina escolar: la historia. Barcelona: Pomares Corredor.

Dussel, I. y Gutiérrez, D. (2006) (comp.) Educar la mirada. Políticas y pedagogías de la imagen. Buenos Aires: Manantial, FLACSO y OSDE.

Dussel, I. (2006). Educar la mirada. Reflexiones sobre una experiencia de producción audiovisual y de formación docente. En: Dussel, I. y Gutiérrez, D. (2006) (comp.). Educar la mirada. Políticas y pedagogías de la imagen. Buenos Aires: Manantial, FLACSO y OSDE.

Dussel, I. (2009). Escuela y cultura de la imagen: los nuevos desafíos. En: Revista Nómadas. (30), abril. Bogotá: Universidad Central. 
Feld, C. y Stites, J. (2009) (Comp.). El pasado que miramos. Memoria e imagen ante la historia reciente. Buenos Aires: Paidós.

Ferreira, J. (2013). La representación de la identidad nacional brasileña en la filmografía de Humberto Mauro en la fase silente. En: Lusnich, A. (2013) (coord.). Representación y revolución en el cine latinoamericano del período clásico-industrial: Argentina, Brasil, México. Madrid: CeAlci- Fundación Carolina. Disponible en: www.fundacioncarolina.es

Ferro, M. (1995). Historia contemporánea y cine. Barcelona: Ariel.

Ferro, M. (2009). El cine es una contrahistoria de la historia oficial. En: Erlij, E. (2009). Entrevista al autor de La Gran Guerra. Se analiza el nexo entre la historia y la imagen audiovisual. Recuperado el 7 de octubre de 2014. http:// www.reporterodelahistoria.com/2009/12/marc-ferroel-cine-es-una.html

Flores, S. (2013). La figura del cangaceiro como emblema de la nacionalidad: del desanclaje social al compromiso histórico-político. En: Lusnich, A. (2013) (coord.). Representación y revolución en el cine latinoamericano del período clásico-industrial: Argentina, Brasil, México. Madrid: CeAlCi- Fundación Carolina. Disponible en: www.fundacioncarolina.es

Fregoso, M. B. (2013). Relación cine y prensa del zapatismo con breves coyunturas del anarquismo argentino, español y brasileño: En: Lusnich, A. (2013) (coord.). Representación y revolución en el cine latinoamericano del período clásico-industrial: Argentina, Brasil, México. Madrid: CeAlCI- Fundación Carolina. Disponible en: www.fundacioncarolina.es

Garavelli, C. (2013). Las aguas bajan turbias, una película revolucionaria a ambos lados del Atlántico. En: Lusnich, A. (2013) (coord.). Representación y revolución en el cine latinoamericano del período clásico-industrial: Argentina, Brasil, México. Madrid: CeAlCi- Fundación Carolina. Disponible en: www.fundacioncarolina.es

García, E. C. (1998). Cine e Historia. Las imágenes de la historia reciente. Madrid: Arco Libros.

Giroux, H. (2003). Cine y entretenimiento. Elementos para una crítica política del filme. Barcelona: Paidós.

Gutiérrez, M. (2014). El cine de autor del cine moderno al cine posmoderno. En: revista Razóny palabra. Recuperado el 16 de febrero del 2015 de: http://www.razonypalabra. org.mx/N/N87/V87/14_Gutierrez_V87_02.pdf

Hueso, L. (1991). Planteamientos historiográficos en el cine histórico. En: Film-Historia, vol. I, n. 1, pp. 13-24. Recuperado el 10 de noviembre de 2014. Disponible en: http://www.raco.cat/index.php/FilmhistoriaOnline/ article/view/225601/306954
Hueso, L. (1998) El cine y el siglo XX. Barcelona: Ariel.

Íber. (1997). Cine, geografía e historia. Barcelona: Graó.

Kracauer, S. (1995). De Caligari a Hitler. Buenos Aires: Nueva Visión.

Lusnich, A. (2013). De la independencia del poder español al dominio de la frontera interior. Claves textuales de los films de ambientación histórica realizados en el período clásico-industrial en Argentina. En: Lusnich, A. (2013) (coord). Representación y revolución en el cine latinoamericano del período clásico-industrial: Argentina, Brasil, México. Madrid: CeALCI-Fundación Carolina. Disponible en: www.fundacioncarolina.es

Masschelein, J. (2006). E-ducar la mirada. La necesidad de una pedagogía pobre. En: Dussel, I. y Gutiérrez, D. (2006) (comp.) Educar la mirada. Políticas y pedagogías de la imagen. Buenos Aires: Manantial, FLACSo y OSDE.

Mercader, Y. (2012) El cine como espacio de enseñanza, producción e investigación. En: Reencuentro, (63), 47-52. México: Universidad Autónoma Metropolitana.

Nóvoa, J., Biscouto, S., y Feigelson, K. (2009) (coord.). Cinematógrafo. Um olhar sobre a História. Sao Paulo: Unesp.

Ordóñez, M. (2011). La docencia de la historia de África subsahariana a través del cine africano. En: Quaderns de Cine (7). 17-28. Disponible en: http://hdl.handle. net/10045/19854

Ospina, C. (2010). Representación de la violencia en la novela del narcotráfico y el cine colombiano contemporáneo. En: Doctoral Dissertations. Paper 45. Recuperado el 11 de junio de 2011, de http://uknowledge.uky. edu/gradschool_diss/45

Paladino, D. (2006). Qué hacemos con el cine en el aula. En: Dussel, I. Gutiérrez, D. (2006) (comp.) Educar la mirada. Políticas y pedagogías de la imagen. Buenos Aires: Manantial, FLACSO y OSDE.

Peña, P. (2012). Memoria, cine y modernidad: una propuesta crítica para aproximarse al pasado. En: Revista Polis, 8 (1).

Pérez, A. (2012). El infierno de Luis Estrada. Una mirada desde el esquizoanálisis de Gilles Deleuze. En: Revista Cultura y representaciones sociales. México: UNAM, 6, (12), 238-261. Recuperado el 6 de febrero de 2013, de http://www.revistas.unam.mx/index.php/crs/ article/view/30482

Pérez, M. (2008). La historia reciente de Colombia a través de su cine. En: Procesos Históricos (014), año VII. Mérida, Venezuela: Universidad de los Andes. 
Pérez, M. y Fernández, D. (2002) (coord.). La memoria filmada. América Latina a través de su cine. Madrid: Editorial Iepala y la Universidad de Cádiz.

Piedras, P. (2013). Las narrativas sobre la Revolución en el cine de Fernando de Fuentes y Emilio Fernández. En: Lusnich, A. (2013) (coord.). Representación y revolución en el cine latinoamericano del período clásico-industrial: Argentina, Brasil, México. Madrid: CeALCI- Fundación Carolina. Disponible en: www.fundacioncarolina.es

Rodríguez, S. y Acosta, W. (2007). La emergencia de la didáctica de las ciencias sociales: ¿campo en consolidación o en disgregación? En: Folios, (25), 37-52. Bogotá: UPN.

Rosenstone, R. (1997). El pasado en imágenes. El desafío del cine a nuestra idea de la historia. Barcelona: Ariel.

Sala. J. (2013). La revolución está en otra parte. La representación de los conflictos del interior del país en el cine clásico-industrial argentino. En: Lusnich, A. (2013) (coord). Representación y revolución en el cine latinoamericano del período clásico-industrial: Argentina, Brasil, México. Madrid: CeALCI- Fundación Carolina. Disponible en: www.fundacioncarolina.es
Salinas, C. (2012). Colonialidad, modernidad y representación en el cine latinoamericano contemporáneo. De Memorias del subdesarrollo a Pizza, Birra, Faso. En: Asthesis, (51).

Sánchez, A. (2000). Escuela, pensamiento crítico y mass media. En: Revista Conciencia Fedicaria. Recuperado el 20 de noviembre de 2014, de http://web.mac.com/ utk1957/iWeb/web_utk/PALABRAS\%20INDEX_files/ ESCUELA_Y_MASS_MEDIA.pdf

Serra, M. (2011). Cine, escuela y discurso pedagógico: articulaciones, inclusiones y objeciones en el siglo XX en Argentina. Buenos Aires: Teseo.

Serra, M. (2012) El cine en la escuela. ¿Política o pedagogía de la mirada? En: Dussel, I. y Gutiérrez, D. (2006) (comp.) Educar la mirada. Políticas y pedagogías de la imagen. Buenos Aires: Manantial, FLACSO y OSDE.

Sorlin, P. (1985). Sociología del cine. La apertura para la historia de mañana. México: Fondo de Cultura Económica.

Valenzuela, L. (2010). En tránsito. Desplazamientos nimios en el cine latinoamericano (2000-2010). En: Aisthesis, (48), 141-154.

Varela, J. y Álvarez, F. (1991). La arqueología de la escuela. Madrid: La Piqueta. 